\title{
The inhibiting effect of the transcription factor p53 on dengue virus infection by activating the type I interferon
}

\author{
Yan-Ling Hu ${ }^{1}$, Xiao-Shan $\mathrm{Li}^{1}$, Shu Xiong ${ }^{1}$, Qiang Ma ${ }^{1}$, Dan Liu ${ }^{1}$, Zhong-Quan Shi ${ }^{1}$, \\ Jing Tang ${ }^{1}$, Xian-Cai Rao' ${ }^{2}$, Fu-Quan Hu${ }^{2}$, Guo-Li Li ${ }^{1}$ \\ ${ }^{1}$ Department of Pathogen Biology and Immunology, Chongqing Three Gorges Medical College, Chongqing 404120, China \\ ${ }^{2}$ Department of Microbiology, The Third Military Medical University, Chongqing 400038, China \\ Correspondence to: Guo-Li Li, email: liguoli_dr@163.com \\ Keywords: dengue virus, p53, apoptosis, interferon, cell apoptosis \\ Received: November 09, $2016 \quad$ Accepted: January 11, $2017 \quad$ Published: February 15, 2017 \\ Copyright: Hu et al. This is an open-access article distributed under the terms of the Creative Commons Attribution License \\ (CC-BY), which permits unrestricted use, distribution, and reproduction in any medium, provided the original author and source \\ are credited.
}

\section{ABSTRACT}

To investigate the role of the transcription factor p53 in the course of the dengue virus (DV) infection. The human hepatocellular carcinoma cell strain HepG2 with a low expression level of p53 was built by using the retroviral-mediated RNA interference technology, and was detected by Western blot. The wild group and the interference group were respectively infected by the type 2 DV. The viral titration was detected by the Vero plaque assay, the viral multiplication was detected by the immunofluorescence, the cell apoptosis after virus infection was detected by FCM and the level of IFN- $\beta$ was analyzed by ELISA. Compared to the wild group, the expression level of p53 in the interference group decreased significantly, which indicated that the HepG2 cell strain with the low expression level of p53 was successfully built. 24h after DV infection, the virus titration in the interference group was 100 times higher than that in the wild group. The result of the immunofluorescence showed that, the amount of green fluorescent cells in the interference group was significant higher than that in the wild group. It was indicated that the DV infection was inhibited by p53. However, 24h after DV infection, there was no significant difference in the amount of apoptotic cells in both groups. And the amount of IFN- $\beta$ in the wild group increased 6 times. The DV infection was inhibited by the transcription factor p53 by activating type I interferon pathway other than promoting the cell apoptosis.

\section{INTRODUCTION}

In normal cells, the transcription factor $\mathrm{p} 53$, with a low expression level, closely relates to the cell cycle, the DNA damage, the cell differentiation and the cell apoptosis [1]. Recent research shows that rats, with p53 gene knocked out, are more susceptible to the virus infection, which indicates that p53 plays an important role in the antivirus infection [2]. Based on current studies, p53 plays an antiviral role in 2 ways. On one hand, at the early stage of virus infection, the viral multiplication can be inhibited by p53 through promoting the secretion of the interferon and the signal transduction. The human papilloma virus, the Kaposi's sarcoma herpesvirus and the poliomyelitis virus can infect the host by specifically disabling p53 [3]. On the other hand, at the late stage of virus infection, the viral multiplication can be inhibited by promoting the infected cell apoptosis. The dengue virus (DV) is the pathogen of the human dengue fever and the dengue hemorrhagic fever/ the dengue shock syndrome (DHF/DSS). This virus can be transmitted by the intermediary aedes which threatens people health in the tropical and the subtropical regions [4]. However, the role of p53 in the DV infection still remains unknown. In this study, in order to further investigate the effect of p53 on the DV infection, the human hepatocellular carcinoma cell strain HepG2 with the wild type p53, and the HepG2 cell strain with the low expression level of p53 were respectively infected by DV. 


\section{RESULTS}

\section{The expression levels of p53 protein in HepG2 cell between two groups}

The WB result showed that the expression level of p53 protein in the interference group was significantly lower than that in the wild group (showed as Figure 1). It showed that the expression level of P53 protein in HepG2 cells was significantly decreased by the recombinant P53
siRNA, and the cell strain with a low expression level of P53 was successfully constructed.

\section{The apoptosis pathway of P53 in HepG2 cell}

The apoptosis was promoted by the 5-FU through activating the signal pathway of P53 [5]. The result of FCM showed that, before the processing of 5-FU, there was no significant difference between the HepG2 cells in the wild group and those in the interference group. $48 \mathrm{~h}$ after adding

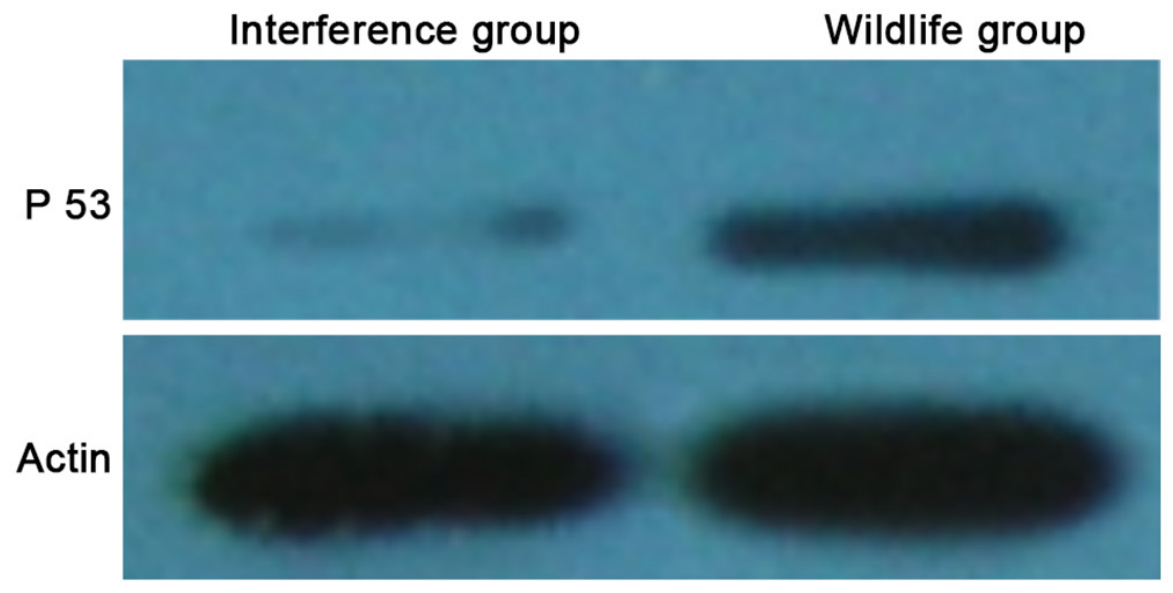

Figure 1: P53 protein levels detected by western blot.
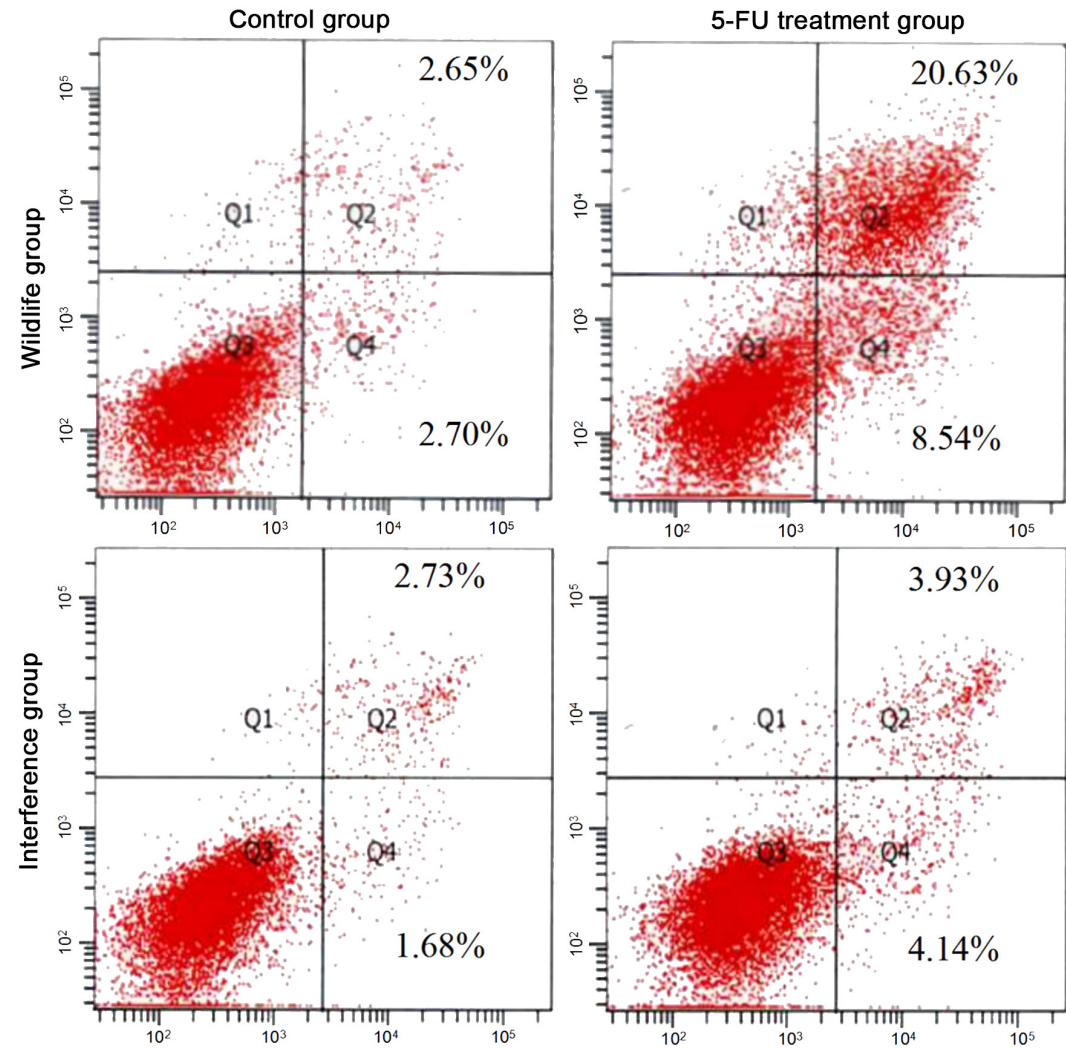

Figure 2: Apoptosis detected by FCM. 
$5-\mathrm{FU}$, the apoptosis rate in the interference group was $3.93 \%$, which was remarkably lower than $20.63 \%$ in the wild group (showed in Figure 2). It showed that the cell apoptosis was promoted by 5-FU through the P53 pathway, and the high apoptosis rate in the wild group also indicated that the apoptosis pathway of P53 in HepG2 cells was normal.

\section{The viral titration}

The result of the plaque assay showed that: 1 day after DV infection, the viral titration in the interference group was 100 times higher than that in the wild group. However, there was no difference between the viral titration in the wild group and that in the interference group at 2 days, 3 days and 4 days after DV infection (showed in Figure 3). It indicated that the DV virus multiplication was inhibited by P53 which happened at the early stage.

The result of the immunofluorescence showed that, when the amount of the cells was equally the same between the groups at $24 \mathrm{~h}$ after DV infection, more virus antigens were found around the nucleus. And the amount

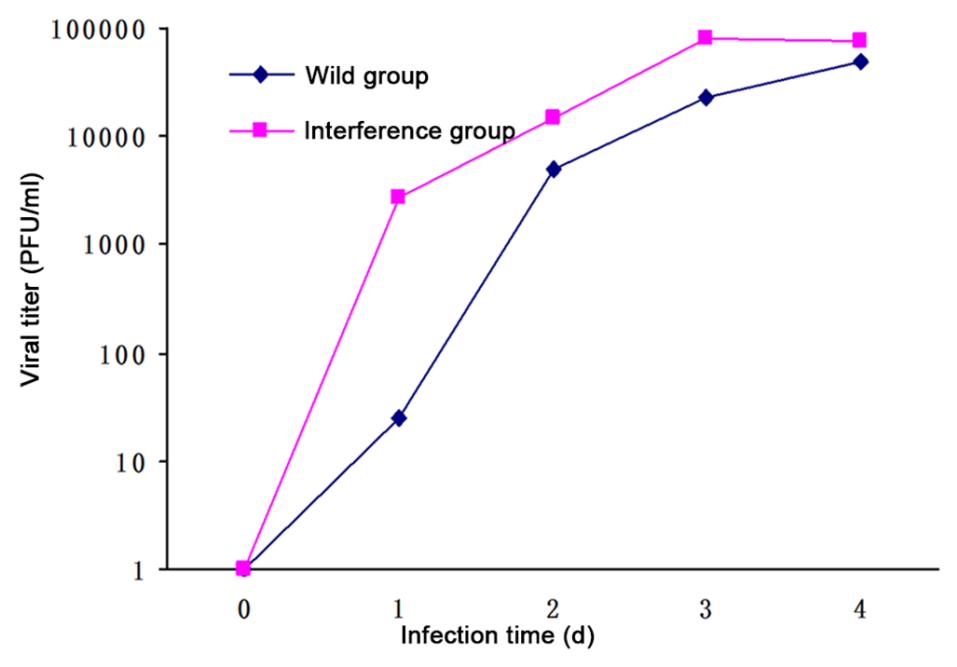

Figure 3: Viral titration detected by the plaque assay.

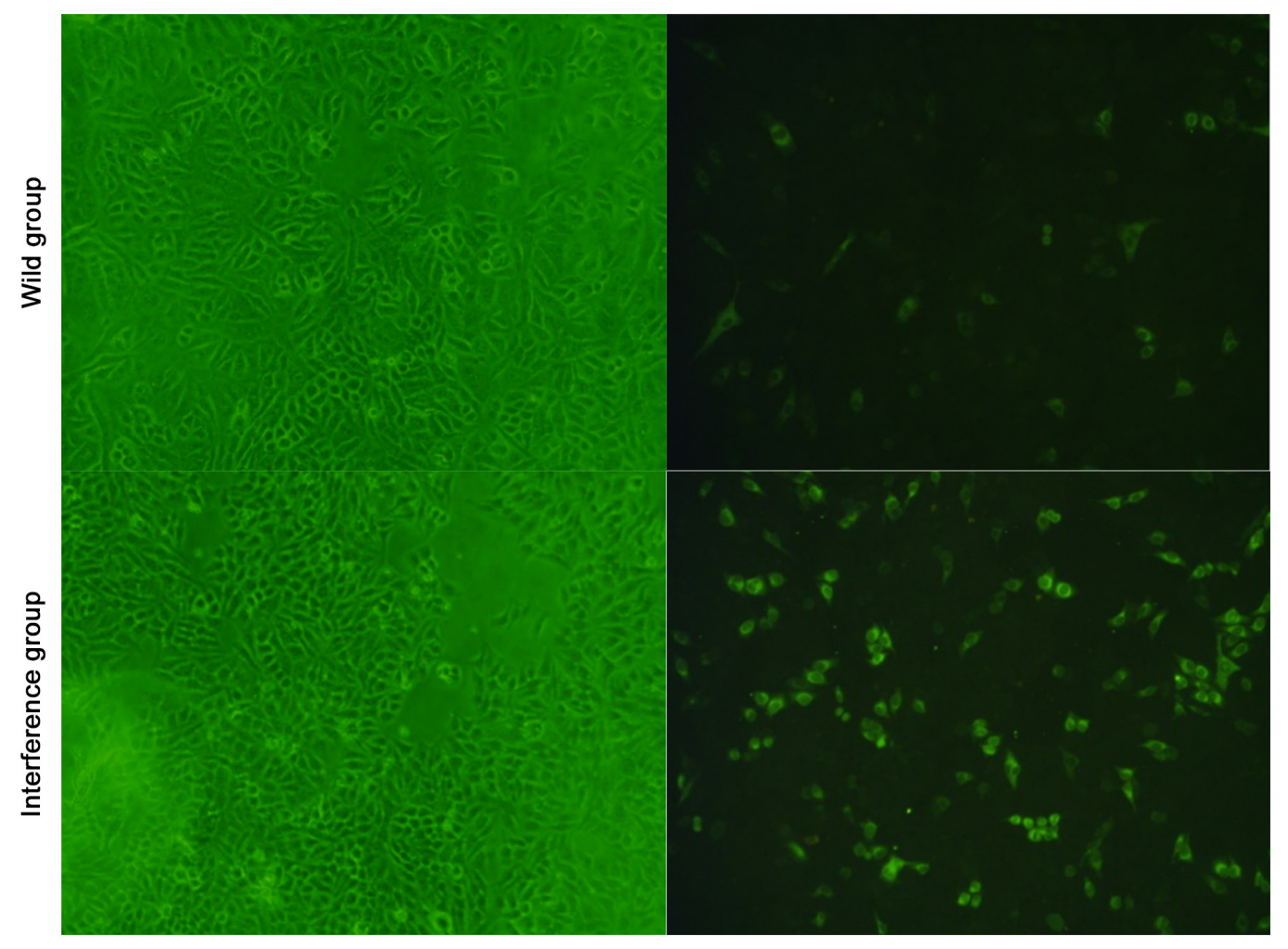

Figure 4: Viral multiplication detected by the immunofluorescence $100 \times$. 
of green fluorescent cells in the interference group was significant higher than that in the wild group (showed in Figure 4). It indicated that the virus multiplication was promoted by the low expression level of P53 in the interference group

\section{The cell apoptosis}

At $24 \mathrm{~h}$ after DV infection, there was no significant difference between the interference group and the control group (showed in Figure 5). The result showed that the antiviral effect of P53 was activated by other pathways instead of the cell apoptosis.

\section{The level of IFN- $\beta$}

The result showed that at $12 \mathrm{~h}$ after DV infection, there was no difference in the levels of IFN- $\beta$ in the wild group and the interference group. At $24 \mathrm{~h}$ after DV infection, the level of IFN- $\beta$ was $6 \mu \mathrm{g} / \mathrm{L}$ in the wild group, however, the level of IFN- $\beta$ in the interference group kept unchanged (shown in Figure 6). It indicated that
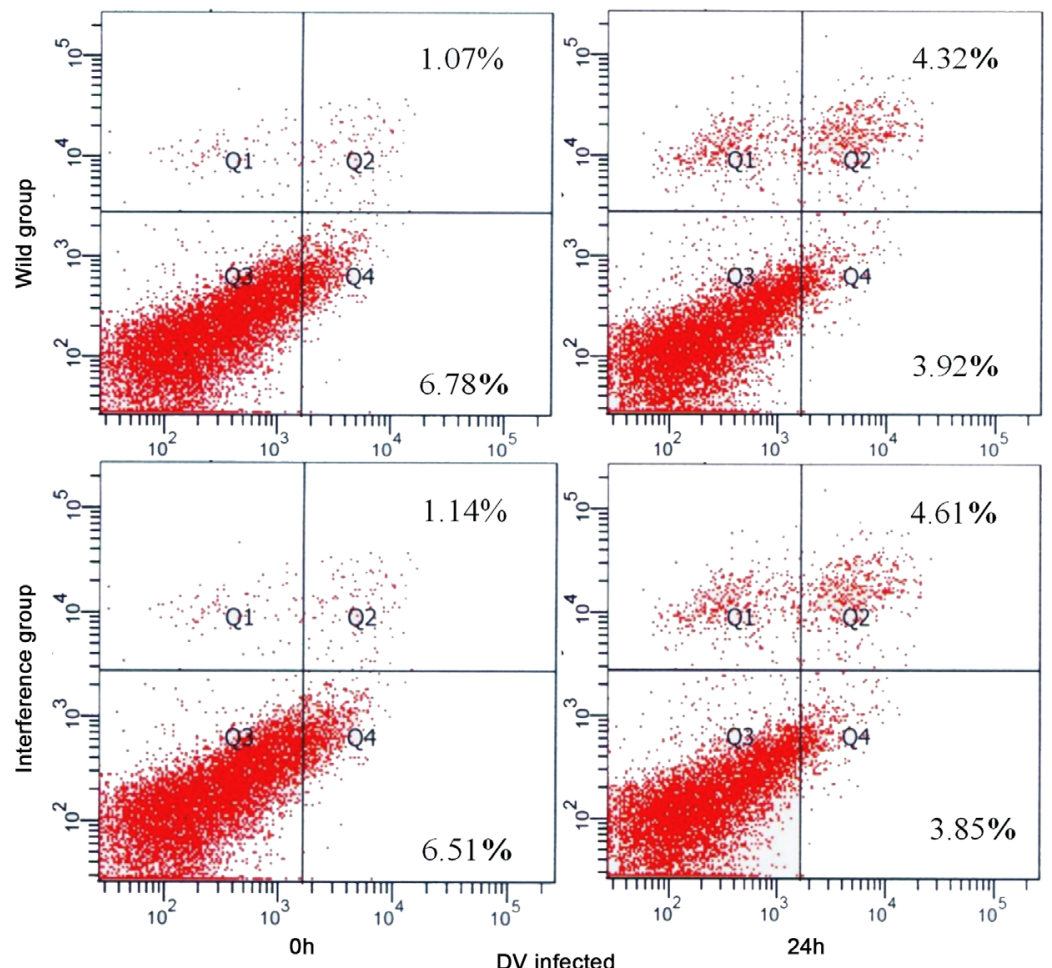

Figure 5: Apoptosis detected by FCM.

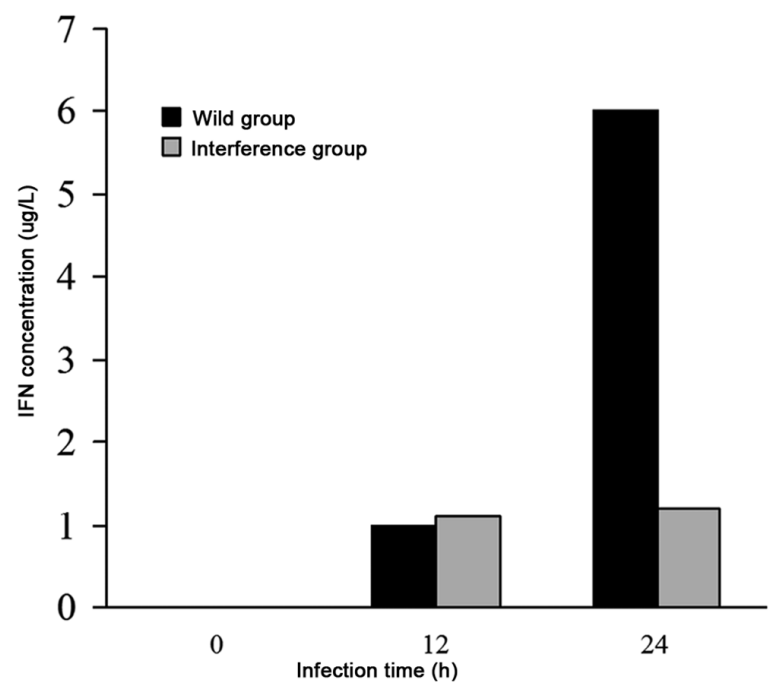

Figure 6: The levels of IFN- $\beta$ analyzed by ELISA. 
the secretion of the interferon in the virus infected cells was promoted by the high expression level of P53, and the interferon played an antiviral role at the early stage of virus infection.

\section{DISCUSSION}

This study showed that, the viral multiplication was inhibited by p53 at the early stage of the DV infection, which was consistent with former literature. Researches show that, the amount of the viral particles released by the p53 deficient cell line is 9 times higher than that released by the wild p53 HepG 2 cell line. It indicates that the release of DV particles is inhibited by p53 [6]. Furthermore, this study found that, in HepG2 the cell apoptosis was not promoted by the p53 pathway after DV infection. Reports, which study about the apoptosis mechanism induced by DV, reveal that the expression level of p53 in the DV infected hepatic cells doesn't increase, and p53 doesn't combine with DV protein. It shows that p53 doesn't participate in the regulation of the apoptosis in the DV infected hepatic cells, which is different from other virus infection [6]. In this study, 24h after DV infection, the amount of IFN- $\beta$ in the wild group was significantly higher than that in the interference group, which indicated that the pathway of p53 antiviral effect related to the increased interferon secretion. Recent researches show that, the virus infection is inhibited by the independent stimulating effect of type I interferon which is mediated by the pattern recognition receptor RIG-I [7]. And IFIT3 has a protective effect on DV infection [8]. Specifically, the antiviral effect of the interferon pathway can be reversed by DV [9] through the interaction between the NS2B/3 protease and $\mathrm{I} \kappa \mathrm{B}$ kinase [10].

Typee I interferon (IFN- $\alpha$ and IFN- $\beta$ ) is secreted by the infected cells, which is induced by the virus infection. And the antiviral effect of non-infected cells can be triggered by the type I interferon. Therefore, the type I interferon is an important molecule of the antiviral innate immunity. The promoter of p53 can combine with the interferon-stimulated response elements (ISREs). Therefore p53 is considered as an activation-induced transcription factor in the downstream of type I interferon signal pathway [11]. In recent researches, the activated p53 can directly combine with the regulatory factor 9 (IRF9) of interferon pathway, which increases the expression level of interferon related genes and the antiviral effect [3]. The secretion of the interferon is promoted by the synergistic effect between the pattern recognition receptor RIG-I, the MDA-5 and the TLR-3, and the viral multiplication is inhibited accordingly [12]. Other reports find out that when DNA is damaged, the antiviral effect of type I interferon induced by p53 is strengthened by the stability of p53-dependent STAT-1 [13]. It indicates that STAT-1 is the targeted gene of the antiviral effect of p53. As for DV infection, the interaction mechanism of the p53 target gene and the interferon pathway still keeps unclear which needs to be further studied.

\section{MATERIALS AND METHODS}

\section{Main materials and equipment}

The HepG2 cell, the DV2 and the DV2 monoclonal antibody were provided by the microbiology laboratory of the Third Military Medical University. The HepG2 cell strain with a low expression level of P53, which was interfered by RNA, was also provided by this laboratory. The 5-FU was purchased from the company Sigma, the FBS and DMEM medium were purchased from the company Gibco. The mouse-anti P53 monoclonal antibody, HRP labeled goat anti-rat IgG and FITC labeled rabbit anti-rat IgG were purchased from the company Santa Cruz. The ECL kit was purchased from the company Thermo, and the human IFN- $\beta$ ELISA detection kit was purchased from MLBIO Company. Annexin V-FITC/PI apoptosis detection kit was purchased from $\mathrm{BD}$. The fluorescence microscope (Olympus Corporation), FCM (BD Company), Trans-Blot and ELIASA (BIO-RAD Company).

\section{The expression level of P53 detection}

The total protein of the recombinant virus infected HepG2 cells and the normal HepG2 cells were respectively extracted, and the Bradford was used for the protein quantification (based on the Bradford protein quantification kit from Beyotime Biotechnology). Western blot was applied in this study. The total protein of the wild HepG2 cells and P53 siRNA HepG2 were isolated by SDS-PAGE and were transferred to the PVDF membrane by using the semidry method. $3 \mathrm{~h}$ after sealing at room temperature, the anti-rat P53 primary antibody was added and both groups were incubated for overnight at $4^{\circ} \mathrm{C}$. Both groups were washed by TBST 3 times and the dilute secondary antibody (HRP labeled goat anti-rat IgG) was added. The samples were vibrant incubated for $1 \mathrm{~h}$ at room temperature, and were washed by TBST 3 times. And all samples were developed in the ECL kit.

\section{The apoptosis rate detection}

The wild HepG2 cell suspension and siRNA HepG2 cell suspension with a low expression level of p53 were inoculated on the 6 -well plate $\left(5 \times 10^{5 /}\right.$ well $)$. When the fusion was $80 \%, 200 \mu \mathrm{g} / \mathrm{mL} 5$-FU was added into each well. $48 \mathrm{~h}$ after incubation, the apoptosis rate was detected by FCM.

\section{Viral titration detection}

p53 HepG2 both in the wild group and the interference group was incubated for $24 \mathrm{~h}$, and washed 
by the DMEM culture medium with $2 \%$ FBS. And DV2((MOI=1) was added and both groups were incubated for $60 \mathrm{~min}$ at $4^{\circ} \mathrm{C}$. The virus bulk was discarded. After adding the DMEM culture medium with $2 \% \mathrm{FBS}$, both groups were incubated in $5 \% \mathrm{CO}_{2}$ incubator at $37^{\circ} \mathrm{C}$. At 1 day, 2 days, 3 days and 4 days after virus infection, the supernatant was respectively collected. The supernatant was diluted to $10^{-1} \sim 10^{-6}$ by the DMEM culture medium with $2 \%$ FBS. And $0.2 \mathrm{ml}$ of the supernatant was inoculated into the one-layer Vero cell. $1 \mathrm{~h}$ after adsorption at $37^{\circ} \mathrm{C}$, the virus bulk was washed off, and $1.5 \mathrm{ml}$ the DMEM culture medium with $1 \%$ methyl cellulose and $2 \%$ FBS were added into each well. When there was no development of the cell lesion, both groups were stained by the crystal violet. The PFU was recorded for calculating the viral titration.

\section{Viral multiplication detection}

$1 \times 10^{5} / \mathrm{ml}$ cells were inoculated on the slides of 6-well plate, and after overnight cultivation the viruses $(\mathrm{MOI}=1)$ were inoculated into the slides. $12 \mathrm{~h}, 24 \mathrm{~h}$ and $48 \mathrm{~h}$ after infection, the slides were fixed by the $4 \%$ paraformaldehyde PBS for $20 \mathrm{~min}$. And PBS with $0.2 \%$ Triton X-100 was added for permeation for $5 \mathrm{~min}$. The slides were sealed by $1 \%$ BSA PBS for $20 \mathrm{~min}$, and later $50 \mu \mathrm{l} /$ pill (DV2 monoclonal antibody) was added. After overnight incubation at $4^{\circ} \mathrm{C}$, the slides were washed by PBS 3 times, $5 \mathrm{~min} /$ per time and the $50 \mu \mathrm{l} /$ pill second antibody (with FITC labeled rabbit anti-rat IgG) was added. After incubation for $1 \mathrm{~h}$ at room temperature, the slides were washed by PBS 3 times, $5 \mathrm{~min} /$ per time. After sealing by $40 \%$ glycerin, the slides were observed under the fluorescence microscope.

\section{The level of IFN- $\beta$ analysis}

$100 \mu \mathrm{l}$ standard substance and $100 \mu \mathrm{l}$ sample were added into the corresponding reaction plate wells. The reaction plate wells were sealed after mixing for $30 \mathrm{~s}$, and were cultivated for $60 \mathrm{~min}$ at $37^{\circ} \mathrm{C} .100 \mu \mathrm{l} 1 \mathrm{x}$ Biotin was added into each well of the reaction plate which was washed 5 times. The reaction plate wells were sealed after mixing for $30 \mathrm{~s}$, and were cultivated for $60 \mathrm{~min}$ at $37^{\circ} \mathrm{C}$. $100 \mu \mathrm{l} 1 \mathrm{x}$ HRP was added into each well of the reaction plate which was washed 5 times. The reaction plate wells were sealed after mixing for $30 \mathrm{~s}$, and were cultivated for $30 \mathrm{~min}$ at $37^{\circ} \mathrm{C} .100 \mu \mathrm{lMB}$ substrate was added into each well of the reaction plate which was washed 5 times. The reaction plate wells were sealed after mixing for $10 \mathrm{~s}$, and were cultivated for $15 \mathrm{~min}$ at $37^{\circ} \mathrm{C}$ in the dark. $100 \mu \mathrm{l}$ stop buffer was added into each well of the reaction plate, which was sealed after mixing for $30 \mathrm{~s}$. At $450 \mathrm{~nm}$, the absorbance values were recorded within $30 \mathrm{~min}$, which were used for calculating the level of IFN- $\beta$ based on the standard curve.

\section{Statistical analysis}

Statistical analysis was performed by using SPSS19.0 software. The data were analyzed by $\mathrm{x} \pm \mathrm{s}$ and the single factor analysis of variance was used. T test was applied to the comparison of multiple means and $\mathrm{P}<0.05$ was considered as statistically significant.

\section{ACKNOWLEDGMENTS AND FUNDING}

This work was supported by the Medical research projects of the Health Bureau of Chongqing, No2011-2411; the Key Projects of Chongqing Three Gorges Medical College, No2016xzzd05.

\section{CONFLICTS OF INTEREST}

We state that we have no conflicts to disclose.

\section{REFERENCES}

1. Wei D, Wu Q, Shi H. Apoptosis and p53 expression in the placental villi of females with unexplained recurrent spontaneous abortion. Exp Ther Med. 2014; 7:191-194.

2. Munoz-Fontela C, Garcia MA, Garcia-Cao I, Collado M, Arroyo J, Esteban M, Serrano M, Rivas C. Resistance to viral infection of super p53 mice. Oncogene. 2005; 24:3059-3062.

3. Muñoz-Fontela C, Macip S, Martínez-Sobrido L, Brown L, Ashour J, García-Sastre A, Lee SW, Aaronson SA. Transcriptional role of $\mathrm{p} 53$ in interferon-mediated antiviral immunity. J Exp Med. 2008; 205:1929-1938.

4. Chisenhall DM, Londono BL, Christofferson RC, McCracken MK, Mores CN. Effect of Dengue-2 Virus Infection on Protein Expression in the Salivary Glands of Aedes aegypti Mosquitoes. Am J Trop Med Hyg. 2014; 90:431-437.

5. Cheng M, He B, Wan T, Zhu W, Han J, Zha B, Chen H, Yang F, Li Q, Wang W, Xu H, Ye T. 5-Fluorouracil nanoparticles inhibit hepatocellular carcinoma via activation of the p53 pathway in the orthotopic transplant mouse mode. PLoS One. 2012; 7: e47115.

6. Thongtan T, Panyim S, Smith DR. Apoptosis in dengue virus infected liver cell lines HepG2 and Hep3B. J Med Virol. 2004; 72:436-444.

7. Olagnier D, Scholte FE, Chiang C, Albulescu IC, Nichols C, He Z, Lin R, Snijder EJ, van Hemert MJ, Hiscott J. Inhibition of dengue and chikungunya virus infections by RIG-I-mediated type I interferon-independent stimulation of the innate antiviral response. J Virol. 2014 ; 88:4180-4194.

8. Hsu YL, Shi SF, Wu WL, Ho LJ, Lai JH. Protective roles of interferon-induced protein with tetratricopeptide repeats 3 (IFIT3) in dengue virus infection of human lung epithelial cells. PLoS One. 2013; 8: e79518. 
9. Green AM, Beatty PR, Hadjilaou A, Harris E. Innate immunity to dengue virus infection and subversion of antiviral responses. J Mol Biol. 2014; 426:1148-1160.

10. Angleró-Rodríguez YI, Pantoja P, Sariol CA. Dengue virus subverts the interferon induction pathway via NS2B/3 protease-IkappaB kinase epsilon interaction. Clin Vaccine Immunol. 2014; 21:29-38.

11. Takaoka A, Hayakawa S, Yanai H, Stoiber D, Negishi H, Kikuchi H, Sasaki S, Imai K, Shibue T, Honda K, Taniguchi $\mathrm{T}$. Integration of interferon-alpha/beta signalling to p53 responses in tumour suppression and antiviral defence. Nature. 2003; 424:516-523.
12. Nasirudeen AM, Wong HH, Thien P, Xu S, Lam KP, Liu DX. RIG-I, MDA5 and TLR3 synergistically play an important role in restriction of dengue virus infection. PLoS Negl Trop Dis. 2011; 5: e926.

13. Youlyouz-Marfak I, Gachard N, Le Clorennec C, Najjar I, Baran-Marszak F, Reminieras L, May E, Bornkamm GW, Fagard R, Feuillard J. Identification of a novel p53dependent activation pathway of STAT1 by antitumour genotoxic agents. Cell Death Differ. 2008; 15:376-385. 